\title{
Homochiral $\beta-\mathrm{CF}_{3},-\mathrm{SCF}_{3}$ and $-\mathrm{OCF}_{3}$ secondary alcohols: catalytic ste- reoconvergent synthesis, bioactivity and flexible crystals
}

\author{
Andrej Emanuel Cotman, ${ }^{*}, \dagger$ Pavel A. Dub, ${ }^{\ddagger}$ Maša Sterle, ${ }^{\dagger}$ Matic Lozinšek,§ Jaka Dernovšek, ${ }^{\dagger}$ Živa \\ Zajec, ${ }^{\dagger}$ Tihomir Tomašič, ${ }^{\dagger}$ Dominique Cahard ${ }^{\diamond}$ \\ † Faculty of Pharmacy, University of Ljubljana, Aškerčeva cesta 7, SI-1000 Ljubljana, Slovenia \\ ₹Chemistry Division, Los Alamos National Laboratory, Los Alamos, New Mexico 87545, United States \\ $\S$ Jožef Stefan Institute, Jamova cesta 39, SI-1000, Ljubljana, Slovenia. \\ $\diamond$ CNRS UMR 6014 COBRA, Normandie Université, 76821 Mont Saint Aignan, France
}

\begin{abstract}
An optimized catalytic protocol for enantio- and diastereoselective reduction of racemic $\alpha-\mathrm{CF}_{3}, \alpha-\mathrm{SCF}_{3}$ and $\alpha$ $\mathrm{OCF}_{3}$ aryl ketones is described. The reaction involves a dynamic kinetic resolution (DKR) based on ruthenium catalyzed Noyori-Ikariya asymmetric transfer hydrogenation for simultaneous construction of two contiguous stereogenic centers. A range of previously inaccessible fluorinated secondary alcohols was prepared in excellent stereomeric purity (up to above 99.9\% ee, up to above 99.9:0.1 dr) and in high isolated yield (up to 99\%). The origin of DKR (exceptional stereoselectivity and racemization mechanism) is rationalized by density functional theory calculations. Pharmaceutically relevant further transformations of the products are demonstrated including incorporation into heat shock protein 90 inhibitor with in vitro anticancer activity. Moreover, needle-shaped crystals of representative stereopure products are mechanically responsive: either elastically or plastically flexible, opening the door to novel class of functional materials based on chiral molecular crystals.
\end{abstract}

Fluorine atom profoundly influences properties of bioactive molecules on multiple levels, which reflects in half of blockbuster drugs and one third of newly Food and Drug Administration-approved drugs being fluoro-pharmaceuticals. ${ }^{1}$ Organofluorine chemistry is essentially man-made as only a dozen fluorinated natural products has been identified on Earth. ${ }^{2}$ The consideration of new fluorinated chemotypes in drug development therefore inevitably follows the availability of the synthetic methods to access the relevant moieties. Outstanding progress was achieved in the preparation of a plethora of synthetic fluorine compounds. ${ }^{3}$ A less developed area being highly challenging while very rewarding is the asymmetric synthesis of stereogenic fluorinated molecules. ${ }^{4}$ In this context, we embarked on the asymmetric construction of chiral carbon atoms featuring a fluorinated motif with emphasis on the trifluoromethyl group $\mathrm{C}^{*}-\mathrm{CF}_{3}$ and its heteroatomic homologues $\mathrm{C}^{*}-\mathrm{SCF}_{3}$ and $\mathrm{C}^{*}-\mathrm{OCF}_{3}$.

In particular, $\beta-\mathrm{CF}_{3}$-substituted alcohols and amines are emerging motifs in medicinal chemistry (Figure 1). For example, Compound I as a mixture of stereomers exhibits antibacterial activity, ${ }^{5}$ and racemic Compound II is an inhibitor of WD repeat-containing protein 5 , which is over-expressed in some types of cancer. ${ }^{6}$ Stereochemically defined trifluoromethylated omarigliptin exhibits better pharmacokinetic and pharmacodynamic profiles compared to the parent drug molecule, and is clinically evaluated as a super long-acting antidiabetic. ${ }^{7}$

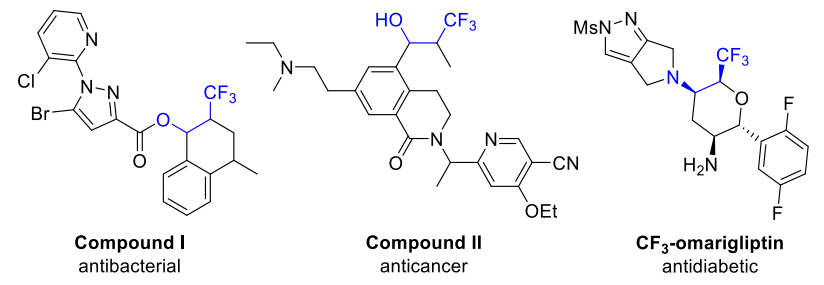

Figure 1. Bioactive compounds with $\beta-\mathrm{CF}_{3}$ alcohol or amine motifs.

Given the potential of stereogenic $\beta-\mathrm{CF}_{3}$-substituted alcohols and amines for medicinal chemistry applications, and eager to use them in our hit-to-lead endeavors, we were surprised to find no preceding literature reports on asymmetric synthesis of the model 2- $\mathrm{CF}_{3}-1$-indanol $2 \mathrm{a}$, its amino analog nor their higher homologues. Non-asymmetric approaches towards such cyclic benzo-fused $\beta$-trifluoromethyl alcohols or amines received significant attention in the past five years, and are based on photoredox, electrochemical or transition metal-catalyzed oxy-trifluoromethylation ${ }^{8}$ or amino-trifluoromethylation ${ }^{9}$ of the corresponding olefins. There is only a handful of literature reports on stereoselective synthesis of $\beta$-trifluoromethyl secondary alcohol motif, based on diastereoselective hydrogenation of 2- $\mathrm{CF}_{3}$ allylic alcohols ${ }^{10}$ or $\mathrm{NaBH}_{4}$ reduction of stereopure $\alpha-\mathrm{CF}_{3}$ ketone, ${ }^{11}$ or diastereoselective aldol or Reformatsky reactions using a chiral auxiliary, ${ }^{12}$ but to the best of our knowledge no catalytic enantioselective access to this class of molecules has ever been reported. 
Dynamic kinetic resolution based on Noyori-Ikariya transfer hydrogenation (DKR-ATH) seemed like a fitting synthetic strategy for addressing the challenging simultaneous control of both chiral centers of the target compound class. ${ }^{13}$ DKR-ATH is a robust method for stereoconvergent access to enantiomerically pure secondary alcohols with multiple contiguous chiral centers starting from the readily available racemic ketones, ${ }^{14}$ including fluorinated examples. ${ }^{15}$ Considering broad availability of the Noyori-Ikariya type ruthenium complexes (Table 1), and their relative stability towards air and moisture, this would offer not only conceptually new but also highly practical access to stereopure $\beta-\mathrm{CF}_{3}$-substituted alcohols and their analogs.

Table 1. Catalyst and solvent screening for Ru(II)-catalyzed DKR-ATH of 1a. ${ }^{a}$

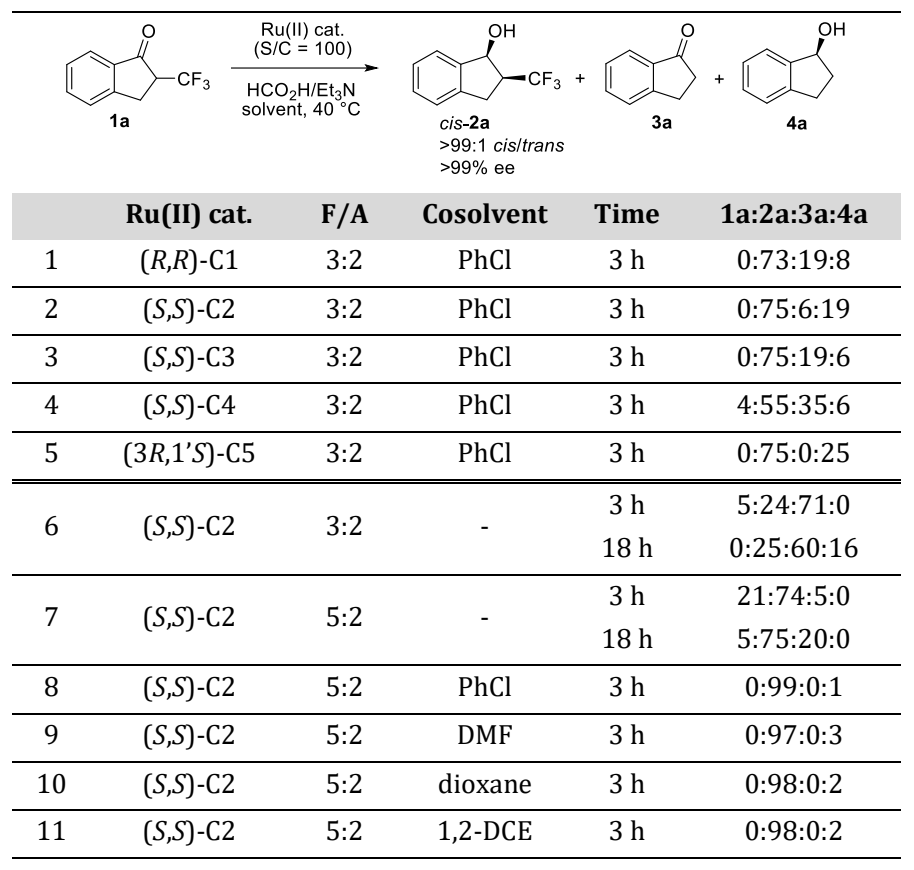

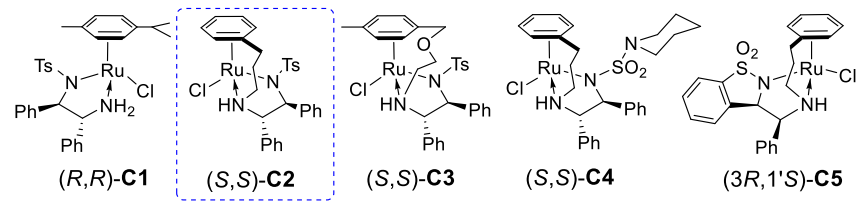

aDKR-ATH of $1 \mathrm{a}(50 \mathrm{mg}, 0.25 \mathrm{mmol})$ was carried out using $\mathrm{Ru}$ (II) cat. (1 mol\%), $\mathrm{HCO}_{2} \mathrm{H} / \mathrm{Et}_{3} \mathrm{~N}(0.25 \mathrm{~mL})$ and cosolvent $(0.5$ $\mathrm{mL}$ ) at $40{ }^{\circ} \mathrm{C}$. The product ratio was determined by NMR analysis of reaction mixture aliquots, and the ratio of $\mathbf{2 a}$ stereomers (cis/trans >99:1; >99\% ee in all cases) was determined after isolation by ${ }^{19} \mathrm{~F}$ NMR and HPLC analysis using chiral stationary phase. F/A equals $\mathrm{HCO}_{2} \mathrm{H} / \mathrm{Et}_{3} \mathrm{~N}$.

A model racemic ketone $2-\mathrm{CF}_{3}-1$-indanone $\mathbf{1 a}$ was prepared in one step by triflic acid mediated annulation of benzene with $2-\mathrm{CF}_{3}$-acrylic acid. ${ }^{16}$ It was subjected to DKR-ATH using commonly used formic acid/triethylamine 3:2 mixture as a source of hydrogen and chlorobenzene as a co-solvent, and five representative Noyori-Ikariya type Ru(II) catalysts were tested (Table 1, runs 1-5). C1 is the archetypical Noyori catalyst, ${ }^{17}$ and the rest are the so-called tethered catalysts, which proved to be superior for the reduction of structurally complex ketones. ${ }^{18}$ Chronologically, C2 was developed by Wills et al., ${ }^{19}$ followed by oxy-tethered catalyst
C3 by Ikariya et al., ${ }^{20}$ sulfamoyl-DPEN-cored C4, ${ }^{21}$ and benzosultam-cored $\mathbf{C 5}$ by Mohar et al. ${ }^{22}$ The reactions using 1 mol\% of catalysts C1-C5 all reached $>95 \%$ conversion within $3 \mathrm{~h}$ (Table 1, entries 1-5). Delightfully, all the catalysts yielded the product $\mathbf{2 a}$ with excellent stereoselectivity $^{23}$ (cis/trans $>99: 1$ and $>99 \%$ ee) as determined by ${ }^{19} \mathrm{~F}$ NMR and chiral HPLC, respectively. The absolute configuration of $2 \mathbf{a}$ being $(S, S)$ was determined by single-crystal Xray diffraction (SCXRD) analysis of a product from run with $(S, S)$-C2. Disappointedly, significant amount of by-product, indanone 3a and/or indanol $\mathbf{4 a}$ (up to $41 \%$ total), was also detected in the reaction mixtures, indicating that an unexpected detrifluoromethylation took place during DKR-ATH. The catalysts performed differently regarding side product formation and $\mathbf{C} \mathbf{2}$ was chosen for further studies because of its wide availability and favorable reaction kinetics (Table S1). Control experiments indicated that trifluoromethyl moiety is eliminated from the ketone 1a rather than the product cis-2a, that it is not a ruthenium-catalyzed process, and involves formation of $\mathrm{Et}_{3} \mathrm{~N} / \mathrm{HF}$ adduct (see SI). To mitigate fluoride elimination, the use of $\mathrm{HCO}_{2} \mathrm{H} / \mathrm{Et}_{3} \mathrm{~N}$ in $5: 2 \mathrm{mo}-$ lar ratio with the most efficient $(S, S)$-C2 was attempted. Performing the DKR-ATH in neat $\mathrm{HCO}_{2} \mathrm{H} / \mathrm{Et}_{3} \mathrm{~N}$ 3:2 or 5:2 (Table 1 , entries 6 and 7) indeed revealed that by increasing the relative amount of formic acid, detrifluoromethylation level dramatically decreases while excellent stereoselectivities are still obtained. Further solvent screening revealed that the use of any cosolvent together with $\mathrm{HCO}_{2} \mathrm{H} / \mathrm{Et}_{3} \mathrm{~N}$ 5:2 was beneficial for the reaction yield as less than $3 \%$ of the side products were observed in chlorobenzene, DMF, 1,4-dioxane or 1,2-dichloroethane (Table 1, entries 8-11). The first one was deemed optimal with only $1 \mathrm{~mol} \%$ of 1 -indanol accompanying the target product $\mathbf{2 a}$.

Computational modeling was further performed to collaborate high level of stereoselectivities and realize the possible mechanism of 1a-racemization being the core process of DKR. The reaction between $\mathbf{1 a}$ and the active form of precatalyst $(S, S)-\mathbf{C} 2$ was studied by M06-2XD3/SMD(chlorobenzene)/def2-qzvp//def2-svp method. Four diastereometic transition states are possible (Figure $2)$. For the $R_{\mathrm{Ru}}, \lambda$-catalyst structural arrangement, ${ }^{24}$ observed in the solid-state of $(S, S)-\mathbf{C} 2,{ }^{19}$ computations predict the ratio of the reaction rates leading to each stereoisomer as $\sim 10^{9}(S, S): 1800(R, R): 400(S, R): 1(R, S){ }^{25}$ This transforms into the cis/trans ratio of $2.5 \times 10^{6}$ and the enantioselectivity of $99.9996 \%$ for the cis product. ${ }^{26}$ The discrepancy between experimentally and theoretically predicted \% ee is likely due to the additional mechanisms of the generation of chirality. ${ }^{27 a}$ However, the calculation reproduces and points to high-level of stereodiscrimination. Two spatial regions of the catalyst simultaneously control the final stereoselectivity: the region of the tethered $\eta^{6}$-arene ligand and the region of the $\mathrm{SO}_{2}$ moiety. ${ }^{27}$ Dynamic equilibrium and interplay of attraction and repulsion in each region through various noncovalent interactions lead to stabilization/destabilization of the corresponding stereoselectivity determining transition state. The presence of $\alpha-\mathrm{CF}_{3}$ functionality is crucial for exceptionally high stereoselectivity. As a comparison, DKR-ATH of 2-methyl-1-indanone using $\mathbf{C} 3$ yielded the corresponding alcohol with a lower cis-selectivity (cis/trans = 98:2, 98\% ee), ${ }^{14 \mathrm{~d}}$ whereas DKR-ATH of 2-acetamido-1-indanone (hydrogen bond donor $\alpha$-substituent) using C5 was even trans-selective (cis/trans $=9: 91) .22 \mathrm{c}$ 

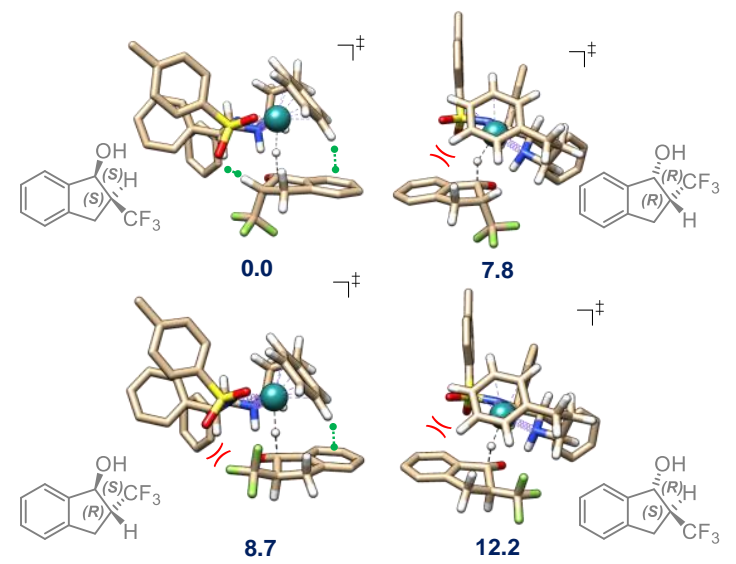

Figure 2. Optimized transition state geometries en route to the four stereomeric products $\mathbf{2 a}$ taking place on $R_{\mathrm{Ru}}, \lambda$-structural arrangement of $(S, S)$-C2 catalyst active form (see text). The relative free energies are given in $\mathrm{kcal} \cdot \mathrm{mol}^{-1}$. Some attractive and repulsive interactions are highlighted by green and red symbols, respectively. Non-crytical H-atoms are omitted for clarity.

A 3:2 mixture of $\mathrm{HCO}_{2} \mathrm{H} / \mathrm{Et}_{3} \mathrm{~N}$ is a typical choice for DKR with Noyori-Ikariya catalysts, ${ }^{28}$ whereas $5: 2$ mixture is usually used for ATH of simple ketones and imines. ${ }^{29}$ Although generally not explained, $\mathrm{Et}_{3} \mathrm{~N}$ or $\mathrm{Et}_{3} \mathrm{~N} / \mathrm{HCO}_{2} \mathrm{H}$ mixture might serve as a catalyst for the DKR-enabling rapid in situ racemization of the $\alpha$-substituted ketones, consistent with the $3: 2$ choice. ${ }^{30}$ Indeed, computations point that direct noncatalyzed epimerization of $\mathbf{1 a}$ is energetically prohibitive (Figure S1, top). On the contrary, 1a-racemization catalyzed by $\mathrm{Et}_{3} \mathrm{~N}$ ("enolate-anion" pathway) and concerted $\mathrm{Et}_{3} \mathrm{~N} / \mathrm{HCO}_{2} \mathrm{H}$ process ("enol" pathway) is energetically plausible with the preference to the former (Figure S1, middle and bottom).

With optimal conditions in hand, we turned our attention to DKR-ATH of various $\alpha$-trifluoromethyl substituted benzo-fused cyclic ketones $\mathbf{1 b}-\mathbf{1 m}$ (Table 2). These were prepared as described for $\mathbf{1 a},{ }^{16}$ via radical desulfur-fragmentation and reconstruction of enol triflates, ${ }^{31}$ and radical trifluoromethylation of the corresponding olefin ${ }^{32}$ or enol acetate, ${ }^{33}$ respectively (see SI). They were all converted to the corresponding stereopure alcohols 2 using the optimized reaction conditions ( 1 mol\% of $\mathbf{C 2}$ in $\mathrm{HCO}_{2} \mathrm{H} / \mathrm{Et}_{3} \mathrm{~N}$ 5:2 and chlorobenzene at $40{ }^{\circ} \mathrm{C}$ ) with reaction times to reach full conversion between 1 and $6 \mathrm{~h}$. Their $(S, S)$-absolute configuration was assigned based on SCXRD analysis of indancored $\mathbf{2 a}, \mathbf{2 d}$, and $\mathbf{2 f}$, and tetralin-cored $\mathbf{2 k}$. The values of cis/trans ratio and enantiomeric excess (ee) in Table 2 are given as ">99" not to oversell the results but the other three possible stereoisomers were in fact present below the limit of detection for most cases, ${ }^{34}$ and the ee of the benzosuberol $\mathbf{2 m}$ was determined to be $99.2 \%$. The tetramethyl substituted indanone 1c required a higher catalyst loading (5 mol\%) to reach full conversion. The reaction yield was affected by detrifluoromethylaton which was generally more expressed during DKR-ATH of indan-cored ketones comparing to their six-membered analogs. 7-Acetamido analog 2h was formed in only $37 \%$ NMR yield with fast decomposition coupled to fast reduction in $\mathrm{HCO}_{2} \mathrm{H} / \mathrm{Et}_{3} \mathrm{~N} 3: 2$, which still outperformed the 5:2 ratio with $25 \%$ NMR yield and full conversion only after $18 \mathrm{~h}$. The decomposition products 3 and $\mathbf{4}$ were nevertheless readily removable by flash chromatography. The tetralin derivatives $\mathbf{1 i}-\mathbf{1 k}$ were devoid of detrifluoromethylation and the corresponding stereopure products $\mathbf{2}$ were isolated directly after extraction.

Table 2. Scope of the DKR-ATH. ${ }^{a}$

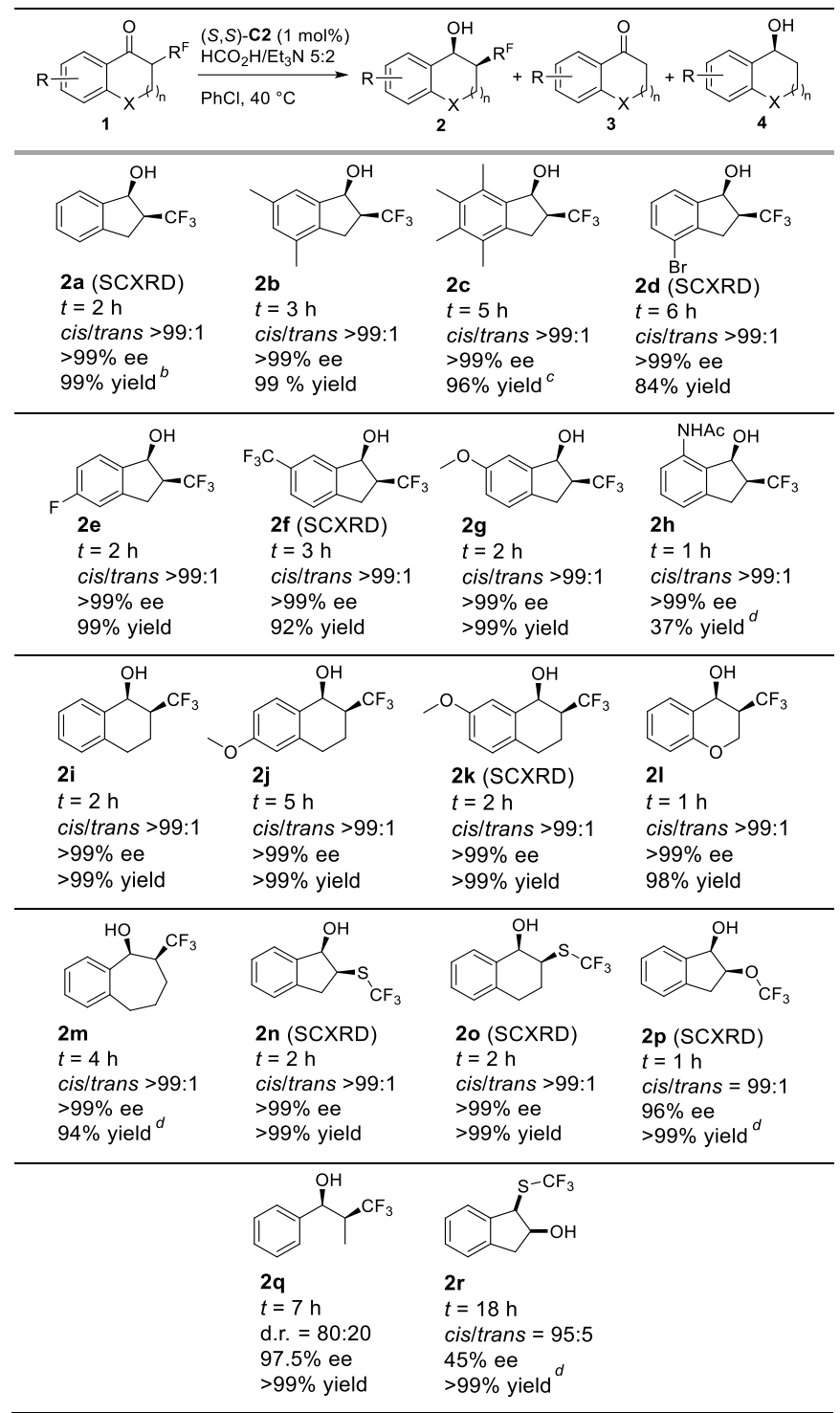

aUnless otherwise specified, the reactions were carried out using $(S, S)-C 2$ (1 mol\%) in $\mathrm{HCO}_{2} \mathrm{H} / \mathrm{Et}_{3} \mathrm{~N} \mathrm{5:2}$ and chlorobenzene at $40^{\circ} \mathrm{C}$. ${ }^{b}$ NMR yield based on integration of 2 relative to 1,3 and 4 . Isolated yields after extraction and optional column chromatography were $1-15 \%$ lower. c $5 \mathrm{~mol} \%$ of $(S, S)-C 2$ used. ${ }^{d} \mathrm{HCO}_{2} \mathrm{H} / \mathrm{Et}_{3} \mathrm{~N}$ 3:2 used.

The method was then extended to the synthesis of stereopure $2-\mathrm{SCF}_{3}$ and $2-\mathrm{OCF}_{3}$ carbinols $\mathbf{2 n}-\mathbf{2} \mathbf{p}$, where no side reactions were observed in either $\mathrm{HCO}_{2} \mathrm{H} / \mathrm{Et}_{3} \mathrm{~N}$ ratio. Stereoselectivities for both trifluoromethylthioethers $\mathbf{2 n}$ and $\mathbf{2 o}$ were determined to be $c i s /$ trans $=99.9: 0.1$ and $99.8 \%$ ee by ${ }^{19} \mathrm{~F}$ NMR and chiral GC, respectively, which gives an estimate of the detection limit. The starting $2-\mathrm{SCF}_{3}$ ketones $\mathbf{1 n}$ and 10 were prepared by means of Billard's reagent under acidic conditions from the corresponding bare ketones. ${ }^{35} 2$ Trifluoromethoxy-1-indanol $\mathbf{2 p}$ was obtained with somewhat lower stereopurity (cis/trans $=99: 1,96 \%$ ee) with the same sense of enantioselectivity (SCXRD analysis); its ketone precursor $\mathbf{1 p}$ was accessed via silver mediated 
oxidative trifluoromethylation of 2-hydroxy-1-indanone. ${ }^{36}$ Pushing it further, the linear analog $\mathbf{1 q}$ was successfully reduced within $7 \mathrm{~h}$ using the same standard conditions delivering the product $\mathbf{2 q}$ as a 3:1 mixture of anti and syn diastereomer with $97.4 \%$ and $90.4 \%$ ee, respectively. The reduction of 1-SCF 3 -2-indanone $1 \mathbf{r}$ to the corresponding alcohol 2r was unfortunately not highly enantioselective (45\% ee) although a 95:5 cis/trans ratio was achieved.

From medicinal chemistry point of view, the stereopure products 2 represent hitherto synthetically inaccessible building blocks featuring intrinsic non-planarity, potential for specific interactions with the protein binding sites, and several growth vectors. ${ }^{37}$ Selected stereopure products 2 were thus prepared on $1 \mathrm{mmol}$ scale, and relevant further synthetic transformations were demonstrated (Scheme 1). $\mathbf{2 g}$ was transformed to trans-configured $\mathbf{5}$ via iron-catalyzed diastereoselective Friedel-Crafts benzylation of 2chloroanisole. ${ }^{38}$ This hydroxy-substituted 1 -arylindan motif is characteristic of resveratrol dimer natural products. ${ }^{39} \mathbf{2 o}$ was converted to azide 6 (trans/cis $=92: 8$ ) via nucleophilic substitution $\left(\mathrm{S}_{\mathrm{N}} 2\right)$ of the corresponding mesylate ester. It was further reduced to the amine $\mathbf{7}$ which was isolated as a single stereomer after chromatography. $\mathbf{2 i}$ was $O$-alkylated to get stereopure clickable building block 8. 2d was converted to biaryl 9 via Suzuki coupling reaction, illustrating that unprotected $2-\mathrm{CF}_{3}$-carbinols are compatible with palladium catalysis. And finally, stereopure 2a and 2c were reoxidized using pyridinium chlorochromate to get enantioenriched 1 a and 1c with $57 \%$ and $92 \%$ ee, respectively. To showcase direct applicability of the developed synthetic methods in a medicinal chemistry setting, alkyne $\mathbf{8}$ was incorporated in $\mathbf{1 0}$ that represents a novel structural class of heat shock protein 90 (Hsp90) inhibitors. Compound 10 was designed using molecular dynamics-derived pharmacophore model (Figure S2) ${ }^{40}$ It was shown to inhibit Hsp90 in luciferase refolding assay and display antiproliferative activity in SkBr3 breast cancer cell line ( $\left.\mathrm{IC}_{50}=51 \pm 2 \mu \mathrm{M}\right)$.

Moreover, we were pleased to find out that some of the novel enantiopure compounds prepared by our method crystallize as needle-shaped crystals which are elastically (2a, 2d, 2p, 4d) or plastically flexible (2o) (Figure 3, and SI). Mechanically responsive molecular crystals are being recognized as an unexplored platform for applications ranging from adaptive systems and actuators to biocompatible devices and all-organic soft robots. ${ }^{41}$ The crystal structures of 2a, 2d, 2o, 2p and 4d exhibit some of the same features that were identified in other crystals with elastic ${ }^{42}$ or plastic deformation behavior. ${ }^{43}$ In particular, a short crystal axis $(\sim 5$ $\AA$ ), anisotropic packing, corrugated crystal packing, and a prominent intermolecular interaction being highly directional (i.e., hydrogen-bonded chains parallel to the short $a$ crystallographic axis in structures with $P 2{ }_{1} 2{ }_{1} 2{ }_{1}$ symmetry and parallel to the short $b$-crystallographic axis in compounds crystallizing in $P 2{ }_{1}$ space group) with much weaker interactions in perpendicular directions. The slippage of molecular layers lined with trifluoromethyl groups has been established to be the mechanism of the observed plastic deformation. ${ }^{43 \mathrm{c}}$ In our case, chiral $\mathrm{OH}$ and indan scaffold clearly also contribute to mechanic responsiveness as detrifluoromethylated bromoindanol $\mathbf{4 d}$ was also to some degree elastically flexible. ${ }^{4}$ For plastically flexible 2o, two polymorphs (RT $P 2{ }_{1}$, and $100 \mathrm{~K} \mathrm{P2}{ }_{1} 2_{1} 2_{1}$ ) were identified.
Scheme 1. Further synthetic transformations of stereopure DKR-ATH products 2.

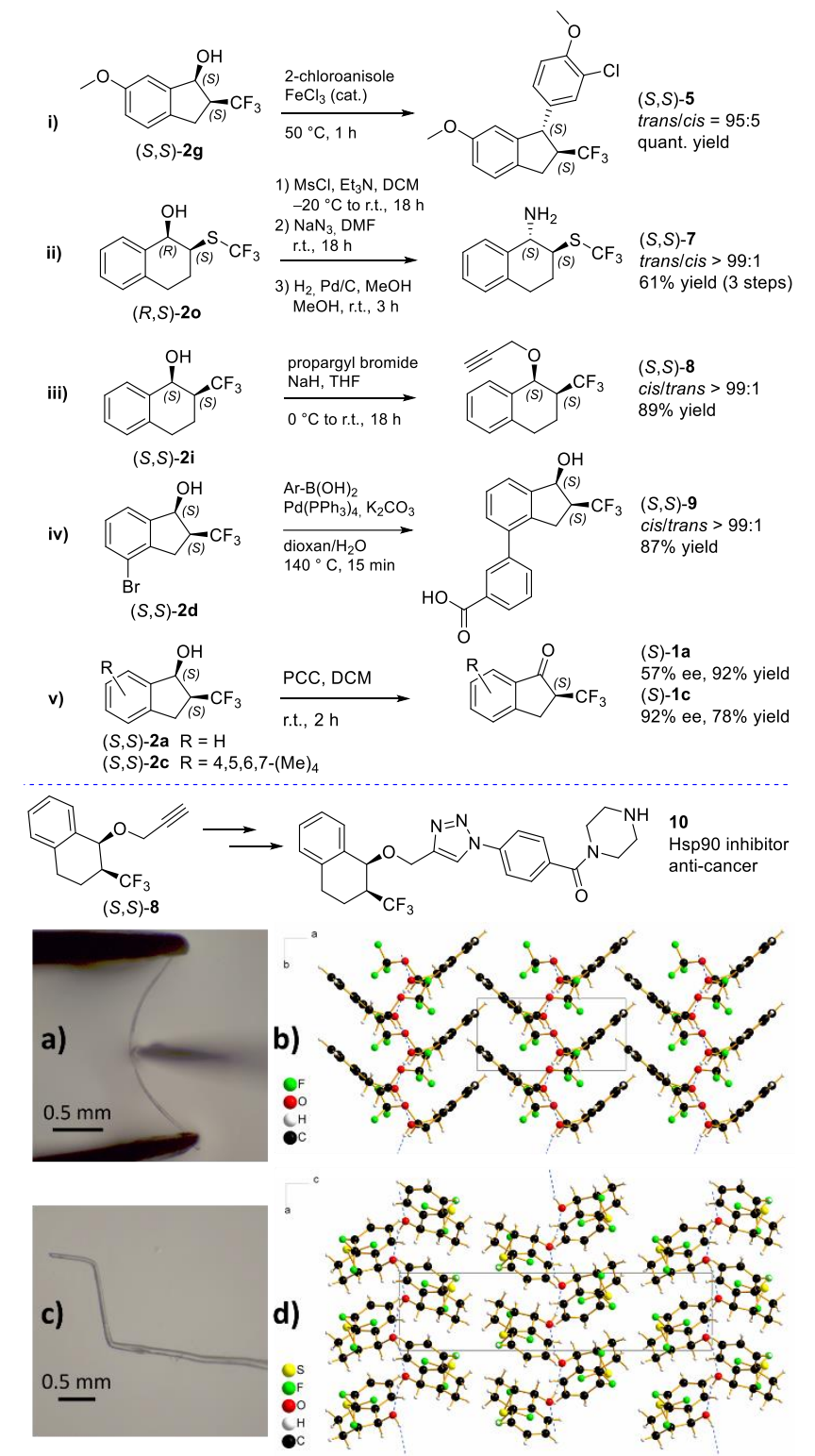

Figure 3. a) Three-point bending experiment with elastically flexible needle-shaped crystal of $\mathbf{2 p}$. b) Crystal packing of $\mathbf{2 p}$, view along $c$ axis. $c$ ) Bent plastically flexible crystal of 2o. d) Crystal packing of $\mathbf{2 0}$, view along $b$ axis.

In conclusion, we have successfully developed a highly efficient dynamic kinetic resolution strategy for the NoyoriIkariya asymmetric transfer hydrogenation of racemic $\alpha$ $\mathrm{CF}_{3}, \alpha-\mathrm{SCF}_{3}$ and $\alpha-\mathrm{OCF}_{3}$ aryl ketones with excellent stereoselectivities (up to above 99.9\% ee, up to above 99.9:0.1 dr). The origin of DKR (in situ epimerization of the ketone substrate, and stereoselectivity) were investigated by DFT calculations. Applicability in the field of medicinal chemistry was demonstrated by several further transformations of the stereopure products including incorporation into in vitro anti-cancer compound. A new class of homochiral small organic molecules, which crystalize as mechanically responsive single-component crystals, was identified. The presented synthetic methodology opens the door to new chiral fluorinated bioactive compounds, and to material science applications based on adaptive chiral molecular crystals. 


\section{ASSOCIATED CONTENT}

\section{Supporting Information.}

The supporting information is available free of charge via the Internet at http://pubs.acs.org.

Experimental procedures, chiral HPLC and GC chromatograms, NMR spectra of the prepared compounds, cell-based assays, computational and SCXRD details, photos of mechanically responsive behavior (PDF).

Movie 2d (AVI)

Movie 4d (AVI)

\section{Accession codes.}

CCDC 2151748-2151755 contain the supplementary crystallographic data for this paper. The data can be obtained free of charge from The Cambridge Crystallographic Data Centre via www.ccdc.cam.ac.uk/structures.

\section{AUTHOR INFORMATION}

\section{Corresponding Author}

* Andrej Emanuel Cotman - Faculty of Pharmacy, University of Ljubljana, Aškerčeva cesta 7, SI-1000 Ljubljana, Slovenia; Email: andrej.emanuel.cotman@ffa.uni-lj.si

\section{Author Contributions}

A. E. C., D. C., P. A. D., T. T. and M. L. conceived and planned the experiments. D. C. carried out the synthesis of fluorinated ketones, A. E. C. and M. S. carried out asymmetric reductions and product characterization, P. A. D. carried out computational mechanistic studies, T. T. and J. D. designed Hsp90 inhibitor, J. D. carried out transformations in Scheme 1, Ž. Z. performed cell-based assays, M. L. performed and interpreted SCXRD analysis and discovered flexibility of the crystals. A. E. C. took the lead in writing the manuscript with input from all authors. All authors have given approval to the final version of the manuscript.

Notes

The authors declare no competing financial interest.

\section{ACKNOWLEDGMENT}

This work was supported by the Slovenian Research Agency ARRS, Grant No. P1-0208, Z1-2635, J1-1717, Centre National de la Recherche Scientifique CNRS, Normandy University, FrenchSlovenian bilateral grant BI-FR/22-23-PROTEUS-004, and Los Alamos Laboratory Directed Research and Development. M. S. acknowledges Anamarija Zega as her PhD supervisor. M. L. gratefully acknowledges the funding by the European Research Council (950625). T.T. acknowledges OpenEye Scientific Software, Santa Fe, NM., for free academic licenses for the use of their software. Maja Frelih is acknowledged for acquisition of HRMS spectra.

\section{REFERENCES}

(1) a) Inoue, M.; Sumii, Y.; Shibata, N. Contribution of Organofluorine Compounds to Pharmaceuticals. ACS Omega 2020, 5, 1063310640. b) Wang, J.; Sánchez-Roselló, M.; Aceña, J. L.; del Pozo, C.; Sorochinsky, A. E.; Fustero, S.; Soloshonok, V. A.; Liu, H. Fluorine in Pharmaceutical Industry: Fluorine-Containing Drugs Introduced to the Market in the Last Decade (2001-2011). Chem. Rev. 2014, 114, 2432-2506. c) Gillis, E. P.; Eastman, K. J.; Hill, M. D.; Donnelly, D. J.; Meanwell, N. A. Applications of Fluorine in Medicinal Chemistry. J. Med. Chem. 2015, 58, 8315-8359. d) Han, J.; Remete, A. M.; Dobson, L. S.; Kiss, L.; Izawa, K.; Moriwaki, H.; Soloshonok, V. A.; O’Hagan, D. Next Generation Organofluorine Containing Blockbuster Drugs. J. Fluorine Chem. 2020, 239, 109639. e) Mei, H.; Remete, A. M.; Zou, Y.; Moriwaki, H.; Fustero, S.; Kiss, L.; Soloshonok, V. A.; Han, J.
Fluorine-Containing Drugs Approved by the FDA in 2019. Chin. Chem. Lett. 2020, 31, 2401-2413. f) Mei, H.; Han, J.; Fustero, S.; Medio-Simon, M.; Sedgwick, D. M.; Santi, C.; Ruzziconi, R.; Soloshonok, V. A., Fluorine-Containing Drugs Approved by the FDA in 2018. Chem. Eur. J. 2019, 25, 11797-11819.

(2) Walker, M. C.; Chang, M. C. Y. Natural and Engineered Biosynthesis of Fluorinated Natural Products. Chem. Soc. Rev. 2014, 43, 6527-6536.

(3) Emerging Fluorinated Motifs: Synthesis, Properties, and Applications. Cahard, D; Ma, J.-A. (Eds), Wiley-VCH Verlag GmbH \& Co. (2020)

(4) a) Meyer, S.; Häfliger, J.; Gilmour, R. Expanding Organofluorine Chemical Space: The Design of Chiral Fluorinated Isosteres Enabled by I(I)/I(III) Catalysis. Chem. Sci. 2021, 12, 10686-10695. b) Zhu, Y.; Han, J.; Wang, J.; Shibata, N.; Sodeoka, M.; Soloshonok, V. A.; Coelho, J. A. S.; Toste, F. D. Modern Approaches for Asymmetric Construction of Carbon-Fluorine Quaternary Stereogenic Centers: Synthetic Challenges and Pharmaceutical Needs. Chem. Rev. 2018, 118, 3887-3964. c) Cahard, D.; Bizet, V., The influence of fluorine in asymmetric catalysis. Chem. Soc. Rev. 2014, 43, 135-147.

(5) Xie, R.; Wu, L. Preparation Method of Trifluoromethyl Tetralone Compound. CN111333613A, June 26, 2020.

(6) Fang, L.; Gao, Z.; Jiang, X.; Liu, K. K. C.; Mak, S. Y. F.; Oyang, C.; Wang, C.; Wang, T.; Wu, J.; Yingming, W.; Xiao, Q. Heterocyclic Wdr5 Inhibitors as Anti-Cancer Compounds. W02021028806A1, February 18, 2021.

(7) Zhang, C.; Ye, F.; Wang, J.; He, P.; Lei, M.; Huang, L.; Huang, A.; Tang, P.; Lin, H.; Liao, Y.; Liang, Y.; Ni, J.; Yan, P. Design, Synthesis, and Evaluation of a Series of Novel Super Long-Acting DPP-4 Inhibitors for the Treatment of Type 2 Diabetes. J. Med. Chem. 2020, 63, 7108-7126.

(8) a) Levitre, G.; Dagousset, G.; Anselmi, E.; Tuccio, B.; Magnier, E.; Masson, G. Four-Component Photoredox-Mediated Azidoalkoxy-Trifluoromethylation of Alkenes. Org. Lett. 2019, 21, 60056010. b) Zhang, L.; Zhang, G.; Wang, P.; Li, Y.; Lei, A. Electrochemical Oxidation with Lewis-Acid Catalysis Leads to Trifluoromethylative Difunctionalization of Alkenes Using $\mathrm{CF}_{3} \mathrm{SO}_{2} \mathrm{Na}$. Org. Lett. 2018, 20, 7396-7399. c) Jud, W.; Kappe, C. O.; Cantillo, D. Catalyst-Free Oxytrifluoromethylation of Alkenes through Paired Electrolysis in Organic-Aqueous Media. Chem. Eur. J. 2018, 24, 17234-17238. d) Valverde, E.; Kawamura, S.; Sekine, D.; Sodeoka, M. Metal-Free Alkene Oxy- and Amino-Perfluoroalkylations via Carbocation Formation by Using Perfluoro Acid Anhydrides: Unique Reactivity between Styrenes and Perfluoro Diacyl Peroxides. Chem. Sci. 2018, 9, 7115-7121. e) Yang, Y.; Liu, Y.; Jiang, Y.; Zhang, Y.; Vicic, D. A. Manganese-Catalyzed Aerobic Oxytrifluoromethylation of Styrene Derivatives Using $\mathrm{CF}_{3} \mathrm{SO}_{2} \mathrm{Na}$ as the Trifluoromethyl Source. J. Org. Chem. 2015, 80, 6639-6648. f) Smirnov, V. 0.; Maslov, A. S.; Kokorekin, V. A.; Korlyukov, A. A.; Dilman, A. D. Photoredox Generation of the Trifluoromethyl Radical from Borate Complexes via Single Electron Reduction. Chem. Commun. 2018, 54, 2236-2239. g) Li, Y.; Studer, A. Tranzition-Metal-Free Trifluoromethylaminoxylation of Alkenes. Angew. Chem. Int. Ed. 2012, 51, 8221-8224. h) Yasu, Y.; Koike, T.; Akita, M. Three-component Oxytrifluoromethylation of Alkenes: Highly Efficient and Regioselective Difunctionalization of $\mathrm{C}=\mathrm{C}$ Bonds Mediated by Photoredox Catalysts. Angew. Chem. Int. Ed. 2012, 51, 9567-9571.

(9) a) Wang, P.; Zhu, S.; Lu, D.; Gong, Y. Intermolecular Trifluoromethyl-Hydrazination of Alkenes Enabled by Organic Photoredox Catalysis. Org. Lett. 2020, 22, 1924-1928. b) Zhu, C.-L.; Wang, C.; Qin, Q.-X.; Yruegas, S.; Martin, C. D.; Xu, H. Iron(II)-Catalyzed Azidotrifluoromethylation of Olefins and $\mathrm{N}$-Heterocycles for Expedient Vicinal Trifluoromethyl Amine Synthesis. ACS Catal. 2018, 8, 50325037. c) Zhang, Y.; Han, X.; Zhao, J.; Qian, Z.; Li, T.; Tang, Y.; Zhang, H.-Y. Synthesis of $\beta$-Trifluoromethylated Alkyl Azides via a Manganese-Catalyzed Trifluoromethylazidation of Alkenes with $\mathrm{CF}_{3} \mathrm{SO}_{2} \mathrm{Na}$ and $\mathrm{TMSN}_{3}$. Adv. Synth. Catal. 2018, 360, 2659-2667. d) Wang, F.; Qi, X.; Liang, Z.; Chen, P.; Liu, G. Copper-Catalyzed Intermolecular Trifluoromethylazidation of Alkenes: Convenient Access to $\mathrm{CF}_{3}$-Containing Alkyl Azides. Angew. Chem. Int. Ed. 2014, 53, 
1881-1886. e) Dagousset, G.; Carboni, A.; Magnier, E.; Masson, G. Photoredox-Induced Three-Component Azido- and Aminotrifluoromethylation of Alkenes. Org. Lett. 2014, 16, 4340-4343. f) Yasu, Y.; Koike, T.; Akita, M. Intermolecular Aminotrifluoromethylation of Alkenes by Visible-Light-Driven Photoredox Catalysis. Org. Lett. 2013, 15, 2136-2139.

(10) Chen, Q.; Qing, F.-L. Stereoselective Construction of the 1,1,1-Trifluoroisopropyl Moiety by Asymmetric Hydrogenation of 2-(Trifluoromethyl)Allylic Alcohols and Its Application to the Synthesis of a Trifluoromethylated Amino Diol. Tetrahedron 2007, 63, 11965-11972.

(11) Trost, B. M.; Wang, Y.; Hung, C.-I. J. Use of $\alpha$-Trifluoromethyl Carbanions for Palladium-Catalysed Asymmetric Cycloadditions. Nat. Chem. 2020, 12, 294-301.

(12) a) Franck, X.; Seon-Meniel, B.; Figadère, B. Highly Diastereoselective Aldol Reaction with $\alpha-\mathrm{CF}_{3}$-Substituted Enolates. Angew. Chem. Int. Ed. 2006, 45, 5174-5176. b) Shimada, T.; Yoshioka, M.; Konno, T.; Ishihara, T. Highly Stereoselective $\mathrm{TiCl}_{4}$-Catalyzed Evans-Aldol and $\mathrm{Et}_{3} \mathrm{Al}$-Mediated Reformatsky Reactions. Efficient Accesses to Optically Active Syn- or Anti- $\alpha$-Trifluoromethyl- $\beta$-Hydroxy Carboxylic Acid Derivatives. Org. Lett. 2006, 8, 1129-1131.

(13) Selected recent reviews: a) Cotman, A. E. Escaping from Flatland: Stereoconvergent Synthesis of Three-Dimensional Scaffolds via Ruthenium(II)-Catalyzed Noyori-Ikariya Transfer Hydrogenation. Chem. Eur. J. 2021, 27, 39-53. b) Betancourt, R. M.; Echeverria, P.-G.; Ayad, T.; Phansavath, P.; Ratovelomanana-Vidal, V. Recent Progress and Applications of Transition-Metal-Catalyzed Asymmetric Hydrogenation and Transfer Hydrogenation of Ketones and Imines through Dynamic Kinetic Resolution. Synthesis 2021, 53, 30-50. c) Echeverria, P.-G.; Ayad, T.; Phansavath, P.; Ratovelomanana-Vidal, V. Recent Developments in Asymmetric Hydrogenation and Transfer Hydrogenation of Ketones and Imines through Dynamic Kinetic Resolution. Synthesis 2016, 48, 25232539. d) Matsunami, A.; Kayaki, Y. Upgrading and Expanding the Scope of Homogeneous Transfer Hydrogenation. Tetrahedron Lett. 2018, 59, 504-513. e) Echeverria, P.-G.; Ayad, T.; Phansavath, P.; Ratovelomanana-Vidal, V. Asymmetric (Transfer) Hydrogenation of Substituted Ketones Through Dynamic Kinetic Resolution. In Asymmetric Hydrogenation and Transfer Hydrogenation; John Wiley \& Sons, Ltd, 2021; pp 129-174.

(14) Selected recent articles: a) Vyas, V. K.; Clarkson, G. J.; Wills, M. Sulfone Group as a Versatile and Removable Directing Group for Asymmetric Transfer Hydrogenation of Ketones. Angew. Chem. Int. Ed. 2020, 59, 14265-14269. b) Wang, F.; Yang, T.; Wu, T.; Zheng, L.S.; Yin, C.; Shi, Y.; Ye, X.-Y.; Chen, G.-Q.; Zhang, X. Asymmetric Transfer Hydrogenation of $\alpha$-Substituted- $\beta$-Keto Carbonitriles via Dynamic Kinetic Resolution. J. Am. Chem. Soc. 2021, 143, 2477-2483. c) Touge, T.; Nara, H.; Kida, M.; Matsumura, K.; Kayaki, Y. Convincing Catalytic Performance of Oxo-Tethered Ruthenium Complexes for Asymmetric Transfer Hydrogenation of Cyclic $\alpha$-Halogenated Ketones through Dynamic Kinetic Resolution. Org. Lett. 2021, 23, 3070-3075. d) Touge, T.; Sakaguchi, K.; Tamaki, N.; Nara, H.; Yokozawa, T.; Matsumura, K.; Kayaki, Y. Multiple Absolute Stereocontrol in Cascade Lactone Formation via Dynamic Kinetic Resolution Driven by the Asymmetric Transfer Hydrogenation of Keto Acids with Oxo-Tethered Ruthenium Catalysts. J. Am. Chem. Soc. 2019 , 141, 16354-16361. e) Gediya, S. K.; Clarkson, G. J.; Wills, M. Asymmetric Transfer Hydrogenation: Dynamic Kinetic Resolution of $\alpha$ Amino Ketones. J. Org. Chem. 2020, 85, 11309-11330. f) Carmona, J. A.; Rodríguez-Franco, C.; López-Serrano, J.; Ros, A.; IglesiasSigüenza, J.; Fernández, R.; Lassaletta, J. M.; Hornillos, V. Atroposelective Transfer Hydrogenation of Biaryl Aminals via Dynamic Kinetic Resolution. Synthesis of Axially Chiral Diamines. ACS Catal. 2021, 11, 4117-4124. g) Zhang, Y.-M.; Zhang, Q.-Y.; Wang, D.-C.; Xie, M.-S.; Qu, G.-R.; Guo, H.-M. Asymmetric Transfer Hydrogenation of Rac- $\alpha$-(Purin-9-yl)Cyclopentones via Dynamic Kinetic Resolution for the Construction of Carbocyclic Nucleosides. Org. Lett. 2019, 21, 2998-3002. h) Luo, Z.; Sun, G.; Wu, S.; Chen, Y.; Lin, Y.; Zhang, L.; Wang, Z. $\eta^{6}$-Arene CH-O Interaction Directed Dynamic Kinetic Resolution - Asymmetric Transfer Hydrogenation (DKR-
ATH) of $\alpha$-Keto/Enol-Lactams. Adv. Synth. Catal. 2021, 363, 30303034. i) More, G. V.; Malekar, P. V.; Kalshetti, R. G.; Shinde, M. H.; Ramana, C. V. Ru-Catalyzed Asymmetric Transfer Hydrogenation of $\alpha$-Acyl Butyrolactone via Dynamic Kinetic Resolution: Asymmetric Synthesis of Bis-THF Alcohol Intermediate of Darunavir. Tetrahedron Lett. 2021, 66, 152831.

(15) a) Šterk, D.; Stephan, M.; Mohar, B. Highly Enantioselective Transfer Hydrogenation of Fluoroalkyl Ketones. Org. Lett. 2006, 8, 5935-5938. b) Cotman, A. E.; Cahard, D.; Mohar, B. Stereoarrayed $\mathrm{CF}_{3}$-Substituted 1,3-Diols by Dynamic Kinetic Resolution: Ruthenium(II)-Catalyzed Asymmetric Transfer Hydrogenation. Angew. Chem. Int. Ed. 2016, 55, 5294-5298. c) Ros, A.; Magriz, A.; Dietrich, H.; Fernández, R.; Alvarez, E.; Lassaletta, J. M. Enantioselective Synthesis of Vicinal Halohydrins via Dynamic Kinetic Resolution. Org. Lett. 2006, 8, 127-130. d) Betancourt, R. M.; Phansavath, P.; Ratovelomanana-Vidal, V. Ru(II)-Catalyzed Asymmetric Transfer Hydrogenation of 3-Fluorochromanone Derivatives to Access Enantioenriched cis-3-Fluorochroman-4-ols through Dynamic Kinetic Resolution. J. Org. Chem. 2021, 86, 12054-12063. e) Wang, T.; Phillips, E. M.; Dalby, S. M.; Sirota, E.; Axnanda, S.; Shultz, C. S.; Patel, P.; Waldman, J. H.; Alwedi, E.; Wang, X.; Zawatzky, K.; Chow, M.; Padivitage, N.; Weisel, M.; Whittington, M.; Duan, J.; Lu, T. Manufacturing Process Development for Belzutifan, Part 5: A Streamlined Fluorination-Dynamic Kinetic Resolution Process. Org. Process Res. Dev. 2021. https://doi.org/10.1021/acs.oprd.1c00242. f) Wehn, P. M.; Rizzi, J. P.; Dixon, D. D.; Grina, J. A.; Schlachter, S. T.; Wang, B.; Xu, R.; Yang, H.; Du, X.; Han, G.; Wang, K.; Cao, Z.; Cheng, T.; Czerwinski, R. M.; Goggin, B. S.; Huang, H.; Halfmann, M. M.; Maddie, M. A.; Morton, E. L.; Olive, S. R.; Tan, H.; Xie, S.; Wong, T.; Josey, J. A.; Wallace, E. M. Design and Activity of Specific Hypoxia-Inducible Factor-2 $\alpha$ (HIF-2 $\alpha$ ) Inhibitors for the Treatment of Clear Cell Renal Cell Carcinoma: Discovery of Clinical Candidate $(S)-3-((2,2-$ Difluoro-1-hydroxy-7-(methylsulfonyl)-2,3-dihydro-1H-inden-4yl)oxy)-5-fluorobenzonitrile (PT2385). J. Med. Chem. 2018, 61, 9691-9721. g) Mohar, B.; Stephan, M.; Urleb, U. Stereoselective Synthesis of Fluorine-Containing Analogues of Anti-Bacterial Sanfetrinem and LK-157. Tetrahedron 2010, 66, 4144-4149. h) Tan, X.; Zeng, W.; Wen, J.; Zhang, X. Iridium-Catalyzed Asymmetric Hydrogenation of $\alpha$-Fluoro Ketones via a Dynamic Kinetic Resolution Strategy. Org. Lett. 2020, 22, 7230-7233.

(16) Prakash, G. K. S.; Paknia, F.; Vaghoo, H.; Rasul, G.; Mathew, T.; Olah, G. A. Preparation of Trifluoromethylated Dihydrocoumarins, Indanones, and Arylpropanoic Acids by Tandem Superacidic Activation of 2-(Trifluoromethyl)Acrylic Acid with Arenes. J. Org. Chem. 2010, 75, 2219-2226.

(17) a) Hashiguchi, S.; Fujii, A.; Takehara, J.; Ikariya, T.; Noyori, R. Asymmetric Transfer Hydrogenation of Aromatic Ketones Catalyzed by Chiral Ruthenium(II) Complexes. J. Am. Chem. Soc. 1995, 117, 7562-7563. b) Haack, K.-J.; Hashiguchi, S.; Fujii, A.; Ikariya, T.; Noyori, R. The Catalyst Precursor, Catalyst, and Intermediate in the $\mathrm{Ru}^{\mathrm{II}}$-Promoted Asymmetric Hydrogen Transfer between Alcohols and Ketones. Angew. Chem. Int. Ed. 1997, 36, 285-288.

(18) G. Nedden, H.; Zanotti-Gerosa, A.; Wills, M. The Development of Phosphine-Free "Tethered" Ruthenium(II) Catalysts for the Asymmetric Reduction of Ketones and Imines. Chem. Rec. 2016, 16, 2623-2643.

(19) Hayes, A. M.; Morris, D. J.; Clarkson, G. J.; Wills, M. A Class of Ruthenium(II) Catalyst for Asymmetric Transfer Hydrogenations of Ketones. J. Am. Chem. Soc. 2005, 127, 7318-7319.

(20) Touge, T.; Hakamata, T.; Nara, H.; Kobayashi, T.; Sayo, N.; Saito, T.; Kayaki, Y.; Ikariya, T. Oxo-Tethered Ruthenium(II) Complex as a Bifunctional Catalyst for Asymmetric Transfer Hydrogenation and $\mathrm{H}_{2}$ Hydrogenation. J. Am. Chem. Soc. 2011, 133, 14960-14963.

(21) Kišić, A.; Stephan, M.; Mohar, B. ansa-Ruthenium(II) Complexes of $\mathrm{R}_{2} \mathrm{NSO}_{2}$ DPEN- $\left(\mathrm{CH}_{2}\right)_{n}\left(\eta^{6}\right.$-Aryl $)$ Conjugate Ligands for Asymmetric Transfer Hydrogenation of Aryl Ketones. Adv. Synth. Catal. 2015, 357, 2540-2546.

(22) a) Rast, S.; Modec, B.; Stephan, M.; Mohar, B. $\gamma$-Sultam-Cored $\mathrm{N}, \mathrm{N}$-Ligands in the Ruthenium(II)-Catalyzed Asymmetric Transfer 
Hydrogenation of Aryl Ketones. Org. Biomol. Chem. 2016, 14, $2112-$ 2120. b) Jeran, M.; Cotman, A. E.; Stephan, M.; Mohar, B. Stereopure Functionalized Benzosultams via Ruthenium(II)-Catalyzed Dynamic Kinetic Resolution-Asymmetric Transfer Hydrogenation. Org. Lett. 2017, 19, 2042-2045. c) Cotman, A. E.; Lozinšek, M.; Wang, B.; Stephan, M.; Mohar, B. trans-Diastereoselective Ru(II)Catalyzed Asymmetric Transfer Hydrogenation of $\alpha$-Acetamido Benzocyclic Ketones via Dynamic Kinetic Resolution. Org. Lett. 2019, 21, 3644-3648.

(23) $(S, S)$-2a was obtained with $(S, S)$-DPEN based catalysts C2, C3 and C4, and $(R, R)$-2a was obtained with $(R, R)$-C1 and $\left(3 R, 1^{\prime} S\right)$ C5.

(24) a) Dub, P. A.; Gordon, J. C. The Mechanism of Enantioselective Ketone Reduction with Noyori and Noyori-Ikariya Bifunctional Catalysts. Dalton Trans. 2016, 45, 6756-6781. b) Hall, A. M. R.; Berry, D. B. G.; Crossley, J. N.; Codina, A.; Clegg, I.; Lowe, J. P.; Buchard, A.; Hintermair, U. Does the Configuration at the Metal Matter in Noyori-Ikariya Type Asymmetric Transfer Hydrogenation Catalysts? ACS Catal. 2021, 11, 13649-13659.

(25) Using absolute rate theory, the ratio of the reaction rates on the two pathways is: $\left.\ln (\mathrm{va} / \mathrm{vb})=\exp \left(-\Delta G_{298 \mathrm{~K}^{\circ}} / R T\right)\right), R T=0.59$ $\mathrm{kcal} \cdot \mathrm{mol}^{-1}$

(26) ee $(\%)=100 \times\left[\exp \left(-\Delta G_{298 \mathrm{~K}^{\circ}} / R T\right)-1\right] /\left[\exp \left(-\Delta G_{298 \mathrm{~K}^{\circ}} / R T\right)+\right.$ $1]$, where $\Delta G_{298 \mathrm{~K}^{\circ}}$ is the free-energy difference in $\mathrm{kcal} \cdot \mathrm{mol}^{-1}$ between the transition states leading to $S$ - and $R$-products, $R T=0.59$ $\mathrm{kcal} \cdot \mathrm{mol}^{-1}$

(27) a) Dub, P. A.; Tkachenko, N. V.; Vyas, V. K.; Wills, M.; Smith, J. S.; Tretiak, S. Enantioselectivity in the Noyori-Ikariya Asymmetric Transfer Hydrogenation of Ketones. Organometallics 2021, 40, 1402-1410. b) Ref. 38b

(28) For molar ratios of triethylamine larger than 0.4, the mixture is biphasic, for this, see Narita, K.; Sekiya, M. Vapor-Liquid Equilibrium for Formic Acid-Triethylamine System Examined by the Use of a Modified Still. Formic Acid-Trialkylamine Azeotropes. Chem. Pharm. Bull. 1977, 25, 135-140.

(29) Selected recent examples: a) Dub, P. A.; Matsunami, A.; Kuwata, S.; Kayaki, Y. Cleavage of N-H Bond of Ammonia via MetalLigand Cooperation Enables Rational Design of a Conceptually New Noyori-Ikariya Catalyst. J. Am. Chem. Soc. 2019, 141, 2661-2677. b) Barrios-Rivera, J.; Xu, Y.; Wills, M. Asymmetric Transfer Hydrogenation of Unhindered and Non-Electron-Rich 1-Aryl Dihydroisoquinolines with High Enantioselectivity. Org. Lett. 2020, 22, 62836287. c) Zheng, Y.; Clarkson, G. J.; Wills, M. Asymmetric Transfer Hydrogenation of O-Hydroxyphenyl Ketones: Utilizing Directing Effects That Optimize the Asymmetric Synthesis of Challenging Alcohols. Org. Lett. 2020, 22, 3717-3721. d) Westermeyer, A.; Guillamot, G.; Phansavath, P.; Ratovelomanana-Vidal, V. Synthesis of Enantioenriched $\beta$-Hydroxy- $\gamma$-Acetal Enamides by Rhodium-Catalyzed Asymmetric Transfer Hydrogenation. Org. Lett. 2020, 22, 3911-3914.

(30) Epimerization is significantly faster using a higher molar ratio of triethylamine. For epimerization kinetics study of $\alpha$-substituted ketone in $\mathrm{HCO}_{2} \mathrm{H} / \mathrm{Et}_{3} \mathrm{~N}$ 3:2 or 5:2, see Ref. 15b

(31) Su, X.; Huang, H.; Yuan, Y.; Li, Y. Radical Desulfur-Fragmentation and Reconstruction of Enol Triflates: Facile Access to $\alpha$-Trifluoromethyl Ketones. Angew. Chem. Int. Ed. 2017, 56, 1338-1341.

(32) Deb, A.; Manna, S.; Modak, A.; Patra, T.; Maity, S.; Maiti, D. Oxidative Trifluoromethylation of Unactivated Olefins: An Efficient and Practical Synthesis of $\alpha$-Trifluoromethyl-Substituted Ketones. Angew. Chem. Int. Ed. 2013, 52, 9747-9750.

(33) Lu, Y.; Li, Y.; Zhang, R.; Jin, K.; Duan, C. Highly Efficient Cu(I)Catalyzed Trifluoromethylation of Aryl(Heteroaryl) Enol Acetates with $\mathrm{CF}_{3}$ Radicals Derived from $\mathrm{CF}_{3} \mathrm{SO}_{2} \mathrm{Na}$ and TBHP at Room Temperature. J. Fluorine Chem. 2014, 161, 128-133.

(34) »There was nothing to integrate« in ${ }^{19} \mathrm{~F}$ NMR spectra at signal/noise $>3000$, and in chiral HPLC or GC spectra of the samples with concentration of $0.5 \mathrm{mg} / \mathrm{mL}$.

(35) Alazet, S.; Ismalaj, E.; Glenadel, Q.; Le Bars, D.; Billard, T. Acid-Catalyzed Synthesis of $\alpha$-Trifluoromethylthiolated Carbonyl Compounds. Eur. J. Org. Chem. 2015, 4607-4610.
(36) Liu, J.-B.; Xu, X.-H.; Qing, F.-L. Silver-Mediated Oxidative Trifluoromethylation of Alcohols to Alkyl Trifluoromethyl Ethers. Org. Lett. 2015, 17, 5048-5051.

(37) a) Goldberg, F. W.; Kettle, J. G.; Kogej, T.; Perry, M. W. D.; Tomkinson, N. P. Designing Novel Building Blocks Is an Overlooked Strategy to Improve Compound Quality. Drug Discovery Today 2015, 20, 11-17. b) Grygorenko, 0. O.; Volochnyuk, D. M.; Vashchenko, B. V. Emerging Building Blocks for Medicinal Chemistry: Recent Synthetic Advances. Eur. J. Org. Chem. 2021, 6478-6510. c) Boström, J.; Brown, D. G.; Young, R. J.; Keserü, G. M. Expanding the Medicinal Chemistry Synthetic Toolbox. Nat. Rev. Drug Discovery 2018, 17, 709-727.

(38) a) Tsoung, J.; Krämer, K.; Zajdlik, A.; Liébert, C.; Lautens, M. Diastereoselective Friedel-Crafts Alkylation of Hydronaphthalenes. J. Org. Chem. 2011, 76, 9031-9045. b) Cotman, A. E.; Modec, B.; Mohar, B. Stereoarrayed 2,3-Disubstituted 1-Indanols via Ruthenium(II)-Catalyzed Dynamic Kinetic Resolution-Asymmetric Transfer Hydrogenation. Org. Lett. 2018, 20, 2921-2924.

(39) a) Keylor, M. H.; Matsuura, B. S.; Stephenson, C. R. J. Chemistry and Biology of Resveratrol-Derived Natural Products. Chem. Rev. 2015, 115, 8976-9027. b) Karageorgis, G.; Foley, D. J.; Laraia, L.; Waldmann, H. Principle and Design of Pseudo-Natural Products. Nat. Chem. 2020, 12, 227-235.

(40) a) Tomašič, T.; Durcik, M.; Keegan, B. M.; Skledar, D. G.; Zajec, Ž.; Blagg, B. S. J.; Bryant, S. D. Discovery of Novel Hsp90 CTerminal Inhibitors Using 3D-Pharmacophores Derived from Molecular Dynamics Simulations. Int. J. Mol. Sci. 2020, 21, 6898. b) Dernovšek, J.; Zajec, Ž.; Durcik, M.; Mašič, L. P.; Gobec, M.; Zidar, N.; Tomašič, T. Structure-Activity Relationships of BenzothiazoleBased Hsp90 C-Terminal-Domain Inhibitors. Pharmaceutics 2021, 13,1283 .

(41) a) Thompson, A. J.; Orué, A. I. C.; Nair, A. J.; Price, J. R.; McMurtrie, J.; Clegg, J. K. Elastically Flexible Molecular Crystals. Chem. Soc. Rev. 2021, 50, 11725-11740. b) Naumov, P.; Karothu, D. P.; Ahmed, E.; Catalano, L.; Commins, P.; Halabi, J. M.; Al-Handawi, M. B.; Li, L. The Rise of the Dynamic Crystals. J. Am. Chem. Soc. 2020, 142, 13256-13272. c) Commins, P.; Karothu, D. P.; Naumov, P. Is a Bent Crystal Still a Single Crystal? Angew. Chem. Int. Ed. 2019, 58, 10052-10060. d) Saha, S.; Mishra, M. K.; Reddy, C. M.; Desiraju, G. R. From Molecules to Interactions to Crystal Engineering: Mechanical Properties of Organic Solids. Acc. Chem. Res. 2018, 51, 2957-2967. e) Reddy, C. M.; Krishna, G. R.; Ghosh, S. Mechanical properties of molecular crystals-applications to crystal engineering. CrystEngComm 2010, 12, 2296-2314.

(42) a) Pisačić, M.; Biljan, I.; Kodrin, I.; Popov, N.; Soldin, Ž.; Đaković, M. Elucidating the Origins of a Range of Diverse Flexible Responses in Crystalline Coordination Polymers. Chem. Mater. 2021, 33, 3660-3668. b) Worthy, A.; Grosjean, A.; Pfrunder, M. C.; Xu, Y.; Yan, C.; Edwards, G.; Clegg, J. K.; McMurtrie, J. C. Atomic Resolution of Structural Changes in Elastic Crystals of Copper(II) Acetylacetonate. Nat. Chem. 2018, 10, 65-69. c) Thompson, A. J.; Price, J. R.; McMurtrie, J. C.; Clegg, J. K. The Mechanism of Bending in CoCrystals of Caffeine and 4-Chloro-3-Nitrobenzoic Acid. Nat. Commun. 2021, 12, 5983. d) Feiler, T.; Michalchuk, A. A. L.; Schröder, V.; List-Kratochvil, E.; Emmerling, F.; Bhattacharya, B. Elastic Flexibility in an Optically Active Naphthalidenimine-Based Single Crystal. Crystals 2021, 11, 1397.

(43) a) Reddy, C. M.; Gundakaram, R. C.; Basavoju, S.; Kirchner, M. T.; Padmanabhan, K. A.; Desiraju, G. R. Structural basis for bending of organic crystals. Chem. Commun. 2005, 3945-3947. b) Reddy, C. M.; Padmanabhan, K. A.; Desiraju, G. R. Structure-Property Correlations in Bending and Brittle Organic Crystals. Cryst. Growth Des. 2006, 6, 2720-2731. c) Bhandary, S.; Thompson, A. J.; McMurtrie, J. C.; Clegg, J. K.; Ghosh, P.; Mangalampalli, S. R. N. K.; Takamizawa, S.; Chopra, D. The Mechanism of Bending in a Plastically Flexible Crystal. Chem. Commun. 2020, 56, 12841-12844.

(44) For a qualitative comparison of elastic flexibility of $\mathbf{2 d}$ and 4d, see attached "Movie 2d" and "Movie 4d". 
